\title{
SIMULIUM (SIMULIUM) WEJI SP. NOV. (DIPTERA: SIMULIIDAE) FROM THAILAND
}

\author{
HIROYUKI TAKAOKA \\ Received August 7, 2001/Accepted November 30, 2001
}

\begin{abstract}
Simulium weji sp. nov. is described based on the reared females, reared males, pupae and mature larvae collected from Tharn Thong Waterfall in Lampang Province, Thailand. This new species is assigned to the tuberosum species-group within the subgenus Simulium s. str., and seems to be closely related to $S$. rufibasis Brunetti and four other allied species, reported from India and Thailand, by having a pair of hair clusters on the ventral surface of the seventh abdominal segment of the female, which are, though, much longer and fewer in this new species. This new species seems to be also related to $S$. nigrifacies Datta from India and $S$. puliense Takaoka from Taiwan, by having the similar arrangement of six short pupal gill filaments, but is easily differentiated from these known species by the small cone-shaped tubercles on the head and thoracic integuments.
\end{abstract}

key words: Black fly, Simuliidae, Simulium, Thailand, New species

Recent investigations on simuliid fauna of Thailand have increased the total number of black-fly species up to 40 (Takaoka and Saito, 1996; Takaoka and Adler, 1997; Takaoka and Kuvangkadilok, 1999; Kuvangkadilok and Takaoka, 2000). During our recent surveys of black flies in northern Thailand we found one more new species belonging to the tuberosum species-group within the subgenus Simulium (Simulium), defined by Takaoka and Davies (1996).

This new species is here described based on the reared females, reared males, pupae and mature larvae.

Holotype and most paratype specimens will be deposited at the Natural History Museum (BMNH), London, U. K.

\section{Simulium (Simulium) weji sp. nov.}

DESCRIPTION. Female. Body length ca. $2.3 \mathrm{~mm}$. Head. Narrower than width of thorax. Frons black, shiny, widely bare except several dark stout hairs along each lateral margin and a few hairs near antennal base; frontal ratio 1.2-1.4: 1.0:1.2; frons-head ratio 1.0:3.7. Fronto-ocular area (Fig. 1) moderately developed, with round lateral tip. Clypeus black, shiny, widely bare medially except dark stout hairs along each lateral margin and several dark stout hairs near lower margin. Proboscis $0.51-0.55 \times$ as long as clypeus. Antenna composed of $2+9$ segments, light to dark brown except scape, pedicel and base of 1st flagellar segment yellow. Maxillary palp brownish black, composed of 5 segments with proportional lengths of 3rd, 4th and 5th segments 1.0:1.3:2.7; 3rd segment (Figs. 2 and 3) of moderate size; sensory vesicle medium in size, ellipsoidal, with rugged surface, ca. $0.3 \times$ length of 3 rd segment, with medium round opening. Maxillary lacinia with 15 or 16 inner and 18 outer teeth. Mandible with ca. 26 inner and 12 outer teeth. Cibarium (Fig. 5) with several minute processes. Thorax. Scutum blackish brown, shiny, not patterned, moderately covered with recumbent dark-brown pubescence, interspersed with long upstanding dark hairs on prescutellar area; scutum thinly grey-pruinose when illuminated in certain angle of light. Scutellum brownish black, with long and short dark hairs. Postscutellum brownish black, shiny, without hairs. Pleural membrane bare. Katepisternum longer than deep, and bare. Legs. Foreleg: coxa whitish yellow; trochanter and femur dark yellow; tibia light brown except apical 1/5 dark brown, and outer surface of basal 4/5 pale white and silvery iridescent in certain angle of light; tarsus entirely brownish black; basitarsus, 2nd and 3rd tarsal segments dilated (basitarsus ca. $4.9 \times$ as long as its greatest width), with distinct dorsal crest of mediumlong hairs. Midleg: coxa brownish black; trochanter light brown with base whitish yellow; femur light brown with apical cap dark brown; tibia light brown except base somewhat yellowish narrowly, with white basal sheen on poste- 
rior surface in certain angle of light; tarsus light brown except basal $4 / 5$ of basitarsus, basal $1 / 3$ or $1 / 2$ of 2 nd tarsal segment and base of 3rd tarsal segment whitish yellow, and 5th tarsal segment brownish black. Hind leg (Fig. 6): coxa medium brown; trochanter whitish yellow; femur medium brown with base whitish yellow and with apical cap dark brown; tibia dark brown to brownish black except base whitish yellow, and with large white sheen on posterior surface in certain angle of light; tarsus dark brown except basal $2 / 3$ of basitarsus and basal $1 / 2$ of 2 nd tarsal segment whitish yellow; basitarsus nearly parallel-sided, ca. $5.8 \times$ as long as its greatest width, and ca. $0.79 \times$ and ca. $0.64 \times$ as wide as hind tibia and femur, respectively; calcipala short, nearly as long as wide, and ca. $0.4 \times$ as wide as greatest width of basitarsus; pedisulcus distinct. All tarsal claws simple, without subbasal or basal tooth. Wing. Length 1.7-1.9 $\mathrm{mm}$; costa with spinules and hairs; subcosta haired; basal section of vein $\mathrm{R}$ bare; hair tuft at base of stem vein dark brown; basal cell absent. Abdomen. Basal scale brownish black with fringe of long hairs; dorsal surface of 2nd segment pale yellow on anterior $1 / 2$ or $2 / 3$ with a pair of large dorsolateral whitish iridescent spots broadly connected to each other in middle; dorsal surface of posterior $1 / 2$ or $1 / 3$ of 2 nd segment and those of other segments dark brown and with dark hairs; tergites 3, 4 and 5 small and dull, tergites 68 large and shiny. Ventral surface of abdominal segment 7 with a pair of submedian clusters of 6 or 7 very long stout hairs (their length range $90-140 \mu \mathrm{m}$ ) on the posterior corner of weakly-developed sternal plates (Fig. 8). Genitalia (Figs. 9 and 10). Sternite 8 well sclerotized, bare medially but with 8-13 short and long stout hairs as well as a few short slender hairs laterally on each side; anterior gonapophysis triangular in shape, membranous, covered with 5 or 6 short hairs as well as numerous microsetae; inner border slightly sinuous, narrowly sclerotized, folded dorsally. Genital fork of inverted-Y form, with well sclerotized stem; arms slender, each with strongly sclerotized apical bulge having a distinct projection directed anteriorly. Paraproct in ventral view nearly as long as wide, with no distinct concavity on ventral surface along anterior margin; anteromedial surface of paraproct strongly sclerotized, and with 5 or 6 short sensilla; paraproct covered with ca. 20 short stout hairs on ventral and lateral surfaces. Cercus in lateral view rounded posteriorly, ca. $0.5 \times$ as long as wide, covered with many short hairs. Spermatheca nearly ovoid, well sclerotized with no definite reticulate pattern, with minute internal setae; tube and small area around tubal base unsclerotized; accessary tubes subequal in diameter to each other and to major one.

Male. Body length 1.9-2.1 mm. Head. Width slightly wider than thorax. Upper eye consisting of large facets in 17 hori- zontal rows and in 16 vertical columns. Clypeus black, white pruinose, and silvery iridescent when illuminated, widely bare except dark stout hairs along each lateral margin and a few dark stout hairs near lower margin. Antenna composed of $2+9$ segments, light to dark brown except 1st, or 1st and $2 \mathrm{nd}$, or 1st to 3rd flagellar segments, as well as scape and pedicel, yellow when viewed ventrally; 1st flagellar segment somewhat elongated, ca. $1.7 \times$ as long as 2 nd flagellomere. Maxillary palp composed of 5 segments, with its proportional length from 3rd to 5th segments 1.0:1.3:2.6; 3rd segment (Fig. 4) of normal size; sensory vesicle small, ellipsoidal, with small opening. Thorax. Scutum black, dull, with white-pruinose shiny pattern composed of an anterior pair of triangular spots with rounded apex (a part of which disappears in certain angles of light) on shoulders, each extending posteriorly forming a broad band along each lateral margin up to base of wing, and a large transverse spot entirely covering prescutellar area, which is narrowly contiguous to each lateral band; these pruinose areas silvery iridescent when illuminated in certain angles of light; scutum uniformly covered with dark-brown recumbent pubescences, interspersed with long upright hairs on prescutellar area. Scutellum brownish black, shiny, with several upright dark hairs. Postscutellum brownish black, shiny, without hairs. Pleural membrane and katepisternum as in female. Legs. Foreleg: coxa whitish yellow; trochanter and femur light brown; tibia medium brown except apical 1/5 dark brown, and outer surface of basal 4/5 narrowly pale white and silvery iridescent in certain angle of light; tarsus entirely brownish black; basitarsus, 2nd and 3rd tarsal segments dilated (basitarsus ca. $4.5 \times$ as long as its greatest width), with distinct dorsal crest of medium-long hairs. Midleg: coxa brownish black; trochanter medium brown with base whitish yellow; femur medium brown with apical cap dark brown; tibia medium brown except base narrowly white; tarsus light brown except basal $4 / 5$ or $5 / 6$ of basitarsus, basal $1 / 3$ of 2 nd tarsal segment and base of 3rd tarsal segment whitish yellow, and 5th tarsal segment brownish black. Hind leg: coxa dark brown; trochanter whitish yellow; femur dark brown with base whitish yellow and with apical cap brownish black; tibia dark brown to brownish black except base whitish yellow; tarsus (Fig. 7) dark brown except basal $3 / 5$ of basitarsus and basal $1 / 2$ of 2 nd tarsal segment whitish yellow; basitarsus (Fig. 7) much enlarged, ca. $3.4 \times$ as long as its greatest width at apical $1 / 4$, and ca. $0.93 \times$ as wide as greatest width of hind tibia which is subequal to that of hind femur. Calcipala small, nearly as long as wide, ca. $0.24 \times$ as wide as greatest width of basitarsus. Pedisulcus well marked. Wing. Length 1.5-1.6 mm; other features as in female except subcosta bare. Abdomen. Basal scale blackish with fringe of long dark hairs. Dorsal 

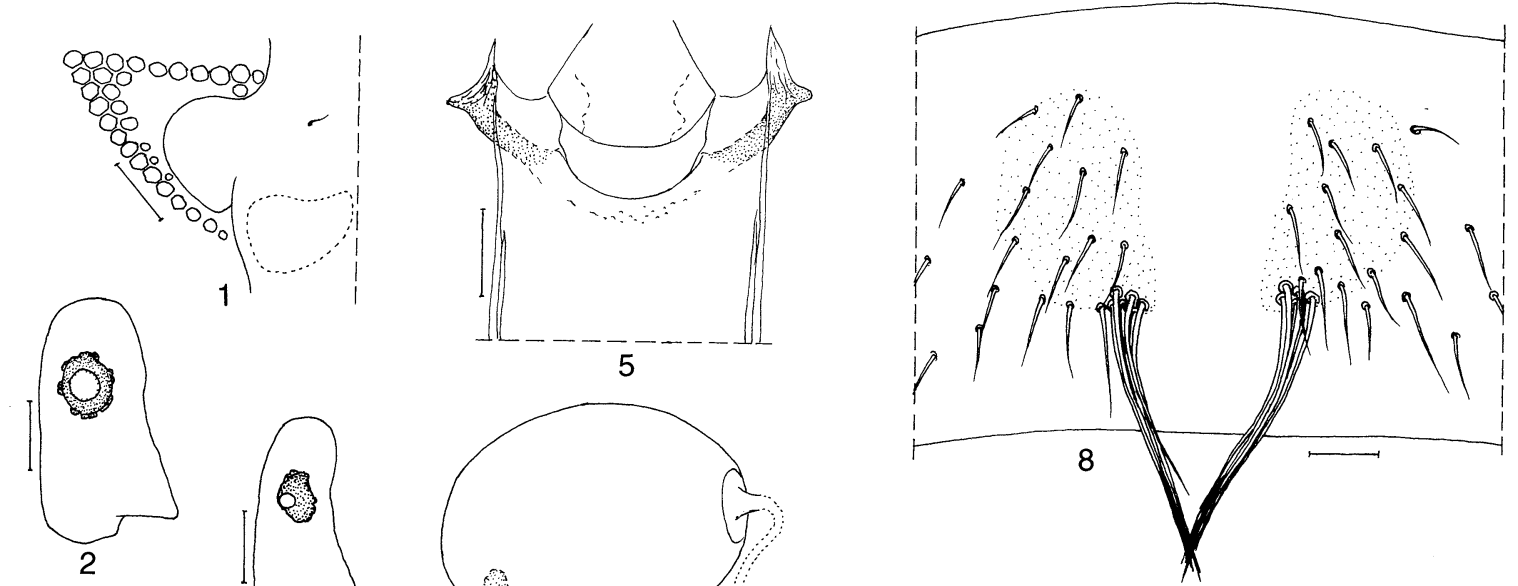

351

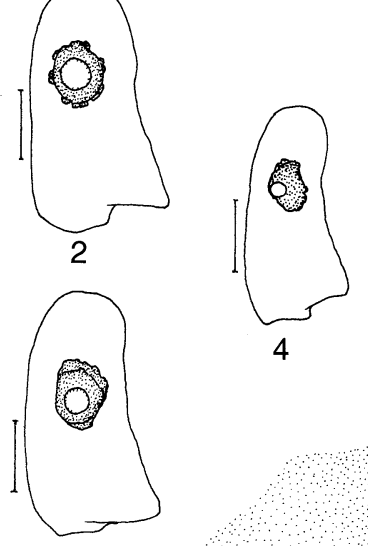

5

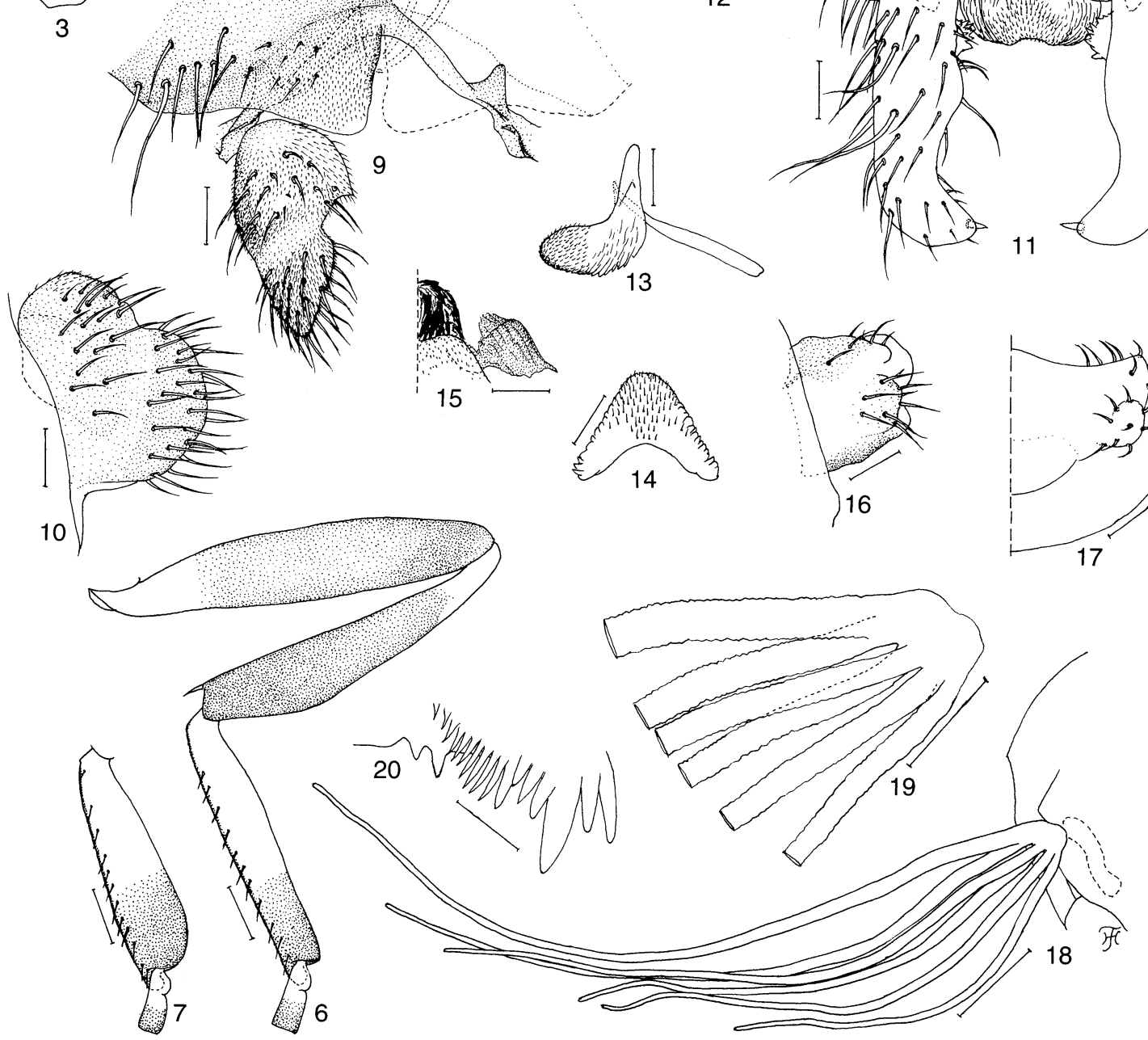

Figures 1-20. Morphological features of $S$. weji sp. nov. 1, female fronto-ocular area; 2-4, 3rd segment of maxillary palp with sensory vesicle ( 2 and 3 , female; 4 , male); 5 , female cibarium; 6 , femur, tibia, basitarsus and 2 nd tarsal segment of female hind leg; 7, basitarsus and 2nd tarsal segment of male hind leg; 8, median portion of the ventral surface of female abdominal segment 7 showing weakly-sclerotized sternal plates and hair clusters; 9, sternite 8, anterior gonapophyses, genital fork, right paraproct, right cercus (left paraproct and cercus omitted) and spermatheca of female genitalia in situ (ventral view); 10, right paraproct and cercus (lateral view); 11, coxites, styles and ventral plate of male genitalia in situ (ventral view); 12, right style showing a spiny basal protuberance (end view); 13, ventral plate and median sclerite (lateral view); 14, ventral plate (end view); 15, left paramere and aedeagal membrane (end view); 16, and 17, 10th abdominal segment and cercus (16, lateral view; 17, end view); 18, pupal gill filaments (left side, lateral view); 19 , basal portion of pupal gill filaments; 20 , apical portion of larval mandible. Scale bars: $0.2 \mathrm{~mm}$ for fig. $18 ; 0.1$ $\mathrm{mm}$ for figs. 6,7 and 19; $0.05 \mathrm{~mm}$ for fig. $1 ; 0.03 \mathrm{~mm}$ for figs. $2-5,8-17 ; 0.02 \mathrm{~mm}$ for fig. 20. 


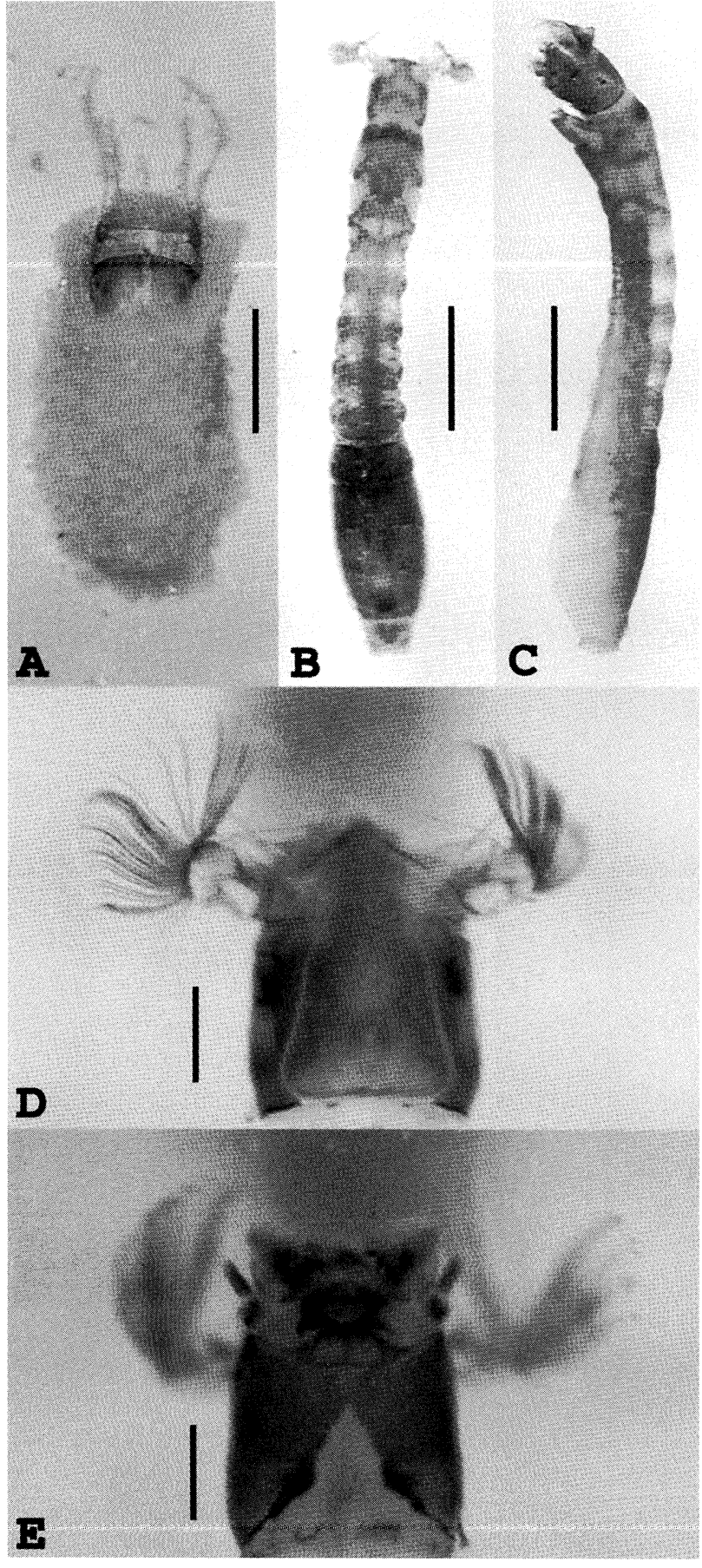

Photographs A-E. Cocoon and larva of $S$. weji sp. nov. A, cocoon and pupal exuvia thickly covered with deposits (probably calcium carbonate); $\mathrm{B}$ and $\mathrm{C}$, mature larva $(\mathrm{B}$, dorsal view; $C$, lateral view); $D$, larval head capsule (dorsal view) showing a negative headspot pattern on cephalic apotome; E, larval head capsule (ventral view) showing a triangular postgenal cleft. Scale bars: 1.0 $\mathrm{mm}$ for photos. A, B and C; $0.2 \mathrm{~mm}$ for photos. D and E. surface of 2nd segment mostly dark yellow except narrow portion along posterior margin medium brown, those of other segments brownish black and with dark hairs; segments 2, 5, 6 and 7 each with a pair of silvery iridescent spots dorsolaterally, those on segment 2 connected broadly to each other in middle, those on other segments connected narrowly to each other anteriorly. Genitalia (Figs. 11-17). Coxite in ventral view nearly quadrate; style elongate, ca. $3.2 \times$ as long as its greatest width near middle, ca. $1.6 \times$ as long as coxite, curved inward from middle to apex, and with a terminal spine; style with basal protuberance produced dorsomedially, bearing numerous spinules on its surface. Ventral plate with base shorter than wide, rounded laterally, concave medially on posterior margin, having a ventrally-produced process which is setose on anterior and posterior surfaces, and with posterolateral margins dentate though becoming indefinite apically; basal arms of ventral plate diverging from each other. Median sclerite moderately sclerotized, plate-like, widening apically, with rounded apex. Parameres broad basally, each with several hooks apically. Aedeagal membrane moderately setose. Abdominal segment 10 with 6 or 7 short hairs on each posterolateral corner ( 4 or 5 ventrally and 2 or 3 laterally). Cerci rounded, each with 7-9 short hairs.

Pupa. Body length (excluding gill filaments) 2.0-2.5 mm. Head. Integument dark yellow to light brown, densely and ellaborately covered with small cone-like tubercles, and with 3 pairs of simple trichomes; 2 frontal trichomes on each side slender and short, $0.4-0.6 \times$ as long as facial medium-long trichome, and moderately separated from each other. Thorax. Integument dark yellow to light brown, densely and ellaborately covered with small conelike tubercles on anterior $1 / 2$, and moderately or sparsely with smaller cone-like tubercles on posterior $1 / 2$; pit-like cuticular organ absent; thorax with 8 pairs of simple medium-long trichomes ( 2 anterodorsally, 2 anterolaterally, 1 posterolaterally and 3 ventrolaterally). Gill (Figs. 18 and 19) with 6 thread-like filaments arranged in 3 pairs; upper pair very shortly stalked but middle and lower pairs almost sessile; filaments of dorsal and middle pairs arising side by side, while those of ventral pair vertically; filaments decreasing in length and diameter from dorsal to ventral with outer filament of dorsal pair longest and thickest of all (1.5$1.7 \mathrm{~mm}$ long), and lower filament of ventral pair shortest (0.5-0.9 mm long); all filaments pale yellow to medium brown, gradually tapered toward apex, with marked annular ridges and furrows (though ridges becoming indistinct apically), densely covered with minute tubercles. Abdomen. Tergum 1 with 1 medium-long simple slender hair on each side. Tergum 2 on each side with 1 medium-long simple 
hair and 4 short simple spinous setae. Terga 3 and 4 each with 4 hooked spines along posterior margin on each side. Terga 5-7 without spine-combs though tergum 7 with a transverse row of comb-like groups of minute spines; terga 8 and 9 each with a transverse row of distinct spine-combs on each side. Tergum 9 without terminal hooks. Sternum 4 with 1 simple hook and 1 simple seta submedially on each side. Sternum 5 with a pair of bifid hooks submedially on each side. Sterna 6 and 7 each with a pair of bifid inner and simple (or bifid) outer hooks, widely spaced on each side. Grapnel-like hooklets absent. Cocoon (Photo. A). Simple, slipper-shaped, tightly woven, not extending ventrolaterally; 2.5-3.0 mm long $\times$ 0.9-1.1 mm wide.

Mature larva. Body length 4.8-5.0 mm. Body color dark greenish on thoracic segment 1 and abdominal segments 58 , and light brown or light green on the rest (Photos. B and C), or almost entirely dark greenish. Cephalic apotome (Photo. D) medium brown with pale areas medially and posteriorly. Lateral and ventral surfaces of head capsule dark brown with negative spots (Photo. E). Antenna composed of 3 segments and apical sensillum, much longer than stem of labral fan; length ratio of segments (from base to tip) 1.0:1.0:0.6. Labral fan with ca. 42 main rays. Mandible (Fig. 20) with mandibular serrations composed of 1 medium tooth and 1 small one, without supernumerary serrations; comb-teeth decreasing in length from 1st to 3rd. Hypostomal teeth 9 in number, median tooth and each corner tooth longer than others; lateral margins moderately serrate apically; 5 or 6 hypostomal bristles diverging posteriorly from lateral border on each side. Postgenal cleft (Photo. E) deep, triangular, pointed anteriorly, ca. $3.1 \times$ as long as postgenal bridge. Thoracic cuticle almost bare. Abdominal cuticle bare except last segment moderately covered with short colorless setae on each side of anal sclerite. Rectal papilla of 3 lobes, each with 14-16 finger-like secondary lobules. Anal sclerite X-shaped, with broadened base, posterior arms ca. $1.4 \times$ as long as anterior ones. Last abdominal segment slightly bulged laterally but lacking ventral papillae. Posterior circlet with ca. 86 rows of hooklets with up to 17 hooklets per row.

TYPE SPECIMENS. Holotype female, slide mounted together with pupal exuvia, Tharn Thong Waterfall, northern Lampang Province, near the border to Lamphun Province, northern Thailand. 15. VI. 2001, by H. Takaoka, W. Choochote, and T. Suntaravitun. Paratypes 5 females, 7 males, 3 pupae, 6 pupal exuviae and 4 mature larvae, same data as holotype.

ECOLOGICAL NOTES. The pupae and larvae of $S$. weji were found to be attached to trailing grasses and stones in a moderately-flowing stream $1.0-3.0 \mathrm{~m}$ wide, exposed to the sun. Most of the pupae and their cocoons of this species, as well as stones in the streambed and submerged trailing grasses, were covered with a thick layer of calcareous sediments (Photo. A). Altitude was $580 \mathrm{~m}$. Water temperature was $23^{\circ} \mathrm{C}$. No other black-fly species was found in the same stream.

ETYMOLOGY. The species name weji is given after Mr. Wej Choochote, Associate professor, Department of Parasitology, Faculty of Medicine, Chiang Mai University, Chiang Mai 50200, Thailand, for his great contribution in the research field of Parasitology and Medical Entomology as well as his kind cooperation during the present survey.

REMARKS. This new species is assigned to the tuberosum species-group within the subgenus Simulium Latreille s. str. by the shape of the genitalia of both sexes and the pupal gill with six filaments per side (Takaoka and Davies, 1996), and seems to be closely related to $S$. rufibasis Brunetti, S. ramosum Puri, and S. fasciatum Puri, all originally described from India (Brunetti, 1911; Puri, 1932), and also to two unnamed species ( $S$. sp. D and $S$. sp. E), reported only from adult female specimens collected together with $S$. rufibasis from Thailand (Takaoka and Suzuki, 1984) by having a pair of hair clusters on the ventral surface of the seventh abdominal segment of the female, which are, though, much longer and fewer in this new species (Fig. 8). The female of $S$. weji is however distinguished from those of all the five known species by the dark hind tibiae leaving only a small pale area basally (Fig. 6) (cf. the hind tibiae of the other species are dark on apical $3 / 5$ to $1 / 2$ and pale on the basal $2 / 5$ to $1 / 2$ ). The pupa of $S$. weji is easily separated from those of $S$. rufibasis and $S$. fasciatum by the almost sessile gill filaments (cf. gill filaments are stalked in the latter two species), and from $S$. ramosum by the simple trichomes on the head and thorax (cf. trichomes are branched in the latter).

This new species seems to be also related to $S$. nigrifacies Datta from India (Datta, 1974) and S. puliense Takaoka from Taiwan (Takaoka, 1979) by having the similar arrangement of the short pupal gill filaments. The female of the latter two species are still unknown. However, the male of these two species are easily separated by the absence of a pair of silvery iridescent spots dorsolaterally on the fifth abdominal segment. In the pupa, there is a slight difference: the tubercles on the head and thoracic integuments are coneshaped in this new species while those are disc-like in $S$. nigrifacies or round in $S$. puliense.

This new species is distinct from $S$. brevipar and $S$. 
tani, both originally described from Peninsular Malaysia (Takaoka and Davies, 1995) and later recorded from Thailand (Takaoka and Saito, 1996), by having the hair clusters on the ventral surface of the seventh abdominal segment in the female, the ventral plate rounded laterally (Fig. 11) in the male, and the cone-shaped tubercles on the head and thoracic integuments in the pupa.

\section{ACKNOWLEDGEMENTS}

I am grateful to Associate Professor Wej Choochote, and Mr. Trenayut Suntaravitun, Department of Parasitology, Chiang Mai University, Chiang Mai, Thailand, for their kind help and arrangement of collections of black flies in northern Thailand. Thanks are due to Dr. Yasushi Otsuka, Department of Infectious Disease Control, Oita Medical Unversity, who kindly took photographs of a cocoon and a larva needed for this paper. This work was financially supported by the Grant-in-Aid of Japan Society for Promotion of Science (the fiscal year 2001).

\section{REFERENCES}

1) Brunetti, E. (1911): New Oriental Nematocera. Rec. Indian Mus., 4, 259-316

2) Datta, M. (1974): Some black flies (Diptera: Simuliidae) of the subgenus Simulium Latreille (s. str.) from the Darjeeling area (India). Oriental Insects, 8, 15-27
3) Kuvangkadilok, C. and Takaoka, H. (2000): Taxonomic notes on Simuliidae (Diptera) from Thailand: Description of a new species and new distributional records of nine known species. Jpn. J. Trop. Med. Hyg., 28, 167-175

4) Puri, I.M. (1932): Studies on Indian Simuliidae. Part II. Descriptions of males, females and pupae of Simulium rufibasis Brunetti, its variety fasciatum nov. var. and of three new species from the Himalayas. Indian J. Med. Res., 19, 899-915

5) Takaoka, H. (1979): The black flies of Taiwan (Diptera: Simuliidae). Pacific Insects, 20, 365-403

6) Takaoka, H. and Adler, P.H. (1997): A new subgenus, Simulium (Daviesellum), and a new species, S. (D.) courtneyi (Diptera: Simuliidae) from Thailand and Peninsular Malaysia. Jpn. J. Trop. Med. Hyg., 25, 17-27

7) Takaoka, H. and Davies, D.M. (1995): The black flies (Diptera: Simuliidae) of West Malaysia. viii +175 p., Kyushu University Press, Fukuoka

8) Takaoka, H. and Davies, D.M. (1996): The black flies (Diptera: Simuliidae) of Java, Indonesia. viii $+81 \mathrm{p}$, Bishop Mus. Bul. Entomol., 6, Bishop Museum Press, Hawaii.

9) Takaoka, H. and Kuvangkadilok, C. (1999): Four new species of black flies (Diptera: Simuliidae) from Thailand. Jpn. J. Trop. Med. Hyg., 27, 497-509

10) Takaoka, H. and Saito, K. (1996): A new species and new records of black flies (Diptera: Simuliidae) from Thailand. Jpn. J. Trop. Med. Hyg., 24, 163-169

11) Takaoka, H. and Suzuki, H. (1984): The blackflies (Diptera: Simuliidae) from Thailand. Jpn. J. Sanit. Zool., 35, $7-45$ 